\title{
The effects of a structured group exercise programme on functional fitness of older persons living in old-age homes
}

\author{
LEVIN CHETTY*, SERELA S. RAMKLASS* and \\ ANDREW J. McKUNE $\dagger$
}

\begin{abstract}
Despite the benefits of exercise, a large percentage of the older population in South Africa continue to lead sedentary lifestyles. This study aimed to determine the effects of a structured group exercise programme on functional fitness of older persons living in old-age homes. A quasi-experimental design was used to compare the effects of a 12-week group exercise programme. Twenty participants each were selected from five old-age homes. Participants were randomly allocated into either an experimental group or a comparison group at each site. The experimental group participated in the exercise intervention three times weekly, while the comparison group received the same intervention twice weekly for 12 weeks. The intervention programme included warm-up, balance, endurance, resistance and cooldown components. Assessments of upper and lower body strength and flexibility, aerobic endurance, agility and balance were conducted before and after the intervention programme using the Senior Functional Test. Comparisons of baseline and post-intervention measures showed greater improvements in upper and lower body strength and flexibility, as well as aerobic endurance capacity $(p<0.05)$. Training frequency revealed no significant difference in functional fitness measures between both groups following the 12 -week intervention programme. Twelve weeks of multifaceted group exercise training, at least twice a week, can be used as an effective strategy to promote functional fitness in this population.
\end{abstract}

KEY WORDS - geriatrics, functional fitness, training frequency, exercise.

\section{Introduction}

By the year $205^{\circ}$, there will be more people over 6o years of age worldwide than children (Lunenfeld 2008). In South Africa, whilst the growth rate may not be as rapid as the developed world, this population is also on the increase. This was confirmed by the latest South African census

* Department of Physiotherapy, University of KwaZulu-Natal, Durban, South Africa.

$\dagger$ Department of Sport and Exercise Science, University of Canberra, Australia. 
which found that the percentage of the population aged 6o years had risen from 7 per cent in 1996 to 8 per cent in 2011 (Statistics South Africa 2012). This constituted an increase from 2.8 million to 4.1 million individuals.

Senescence is closely related to increased chronic impairments resulting in disabilities (Lopez et al. 2006; North and Sinclair 2012). Participation in regular exercise drastically reduces the risk of disabilities while producing significant physical and psychological health benefits (Daley and Spinks 200o). A structured plan of enhanced physical activity has been shown to improve health and quality of life in the older population and these in turn impact preservation of functional capacity and subsequently reduce medical management costs (Duthie and Malone 2007).

Despite these benefits, a high percentage of older adults in South Africa continue to lead a sedentary lifestyle. This high prevalence of physical inactivity, in terms of attributable deaths, ranks ninth compared to other risk factors (Joubert et al. 2007). Insufficient levels of physical activity have been shown to cause a physical decline that will eventually lead to functional limitations in basic tasks such as lifting, stooping, walking or climbing stairs - all of which are daily requirements of independent functioning (Rikli 2005). While the need and development of age-appropriate tools to evaluate the physiological attributes (strength, endurance, flexibility, agility and balance) required in performing activities of daily living have been explored to a certain degree, the effects of frequency of exercise also require further investigation (Marques et al. 2011; Wilkin and Haddock 2011). Significant strength improvements were noted in older adults following participation in a strength training programme twice a week for 12 weeks (Brown and Holloszy 1993). Wolfson et al. (1996) reported improvements in dynamic balance following participation in a training programme three times a week for 12 weeks (Wolfson et al. 1996). Other studies demonstrate that exercise conducted two or more times a week can provide adequate improvements (Chin A Paw et al. 2004; Paw et al. 2006). However, very few efforts have been made to establish how frequently those who are 6o years and older should exercise to gain improvements in functional fitness levels (Nakamura et al. 2007).

There is no evidence in South Africa to date evaluating structured exercise programmes for older populations residing in aged care facilities. The aim of this study was to assess the effect of frequency of a structured exercise programme developed specifically for individuals who are 60 years and older, and reside at aged care facilities, on functional fitness levels. 


\section{Methods}

Design

An experimental research design approach was used to compare the effects of a 12 -week group exercise programme on two groups of participants.

\section{Population}

The population was all persons 6o years and older permanently residing in aged care facilities in the eThekwini municipality.

\section{Sampling strategy}

A listing of all aged care facilities located within a 20-30 kilometre radius of the Durban Central Business District was obtained from the Department of Social Development. Five aged care facilities were randomly selected. Volunteers meeting the study's inclusion/exclusion criteria were invited to a pre-selection screening process to determine eligibility, after which all eligible participants were invited on to the programme. No formal sample size was calculated at the start of the study. There were no results from previous studies in this context to guide the sample size. However, in accordance with the performance of group exercise, a conservative number of not more than 20 participants is considered effective for monitoring changes during group exercise sessions (Armitage-Johnson 1994). In this regard, a quota of 20 participants per site was considered maximum. In the event that numbers were in excess of this quota, simple random sampling using the fishbowl technique (Brink, Van der Walt and Van Rensburg 2012) was used to identify 20 participants (Figure 1). Thereafter, every participant randomly selected a number from 1 to 20 to determine participation in either Group 1 or Group 2. Systemic sampling was used to identify ten participants for Group 1 (all odd numbers) and ten participants for Group 2 (all even numbers).

\section{Intervention procedure and data collection}

The study protocol was approved by the University of KwaZulu-Natal (UKZN) Biomedical Research Ethics Committee (BE o8o/14). Functional fitness levels were assessed prior to the intervention to establish a baseline, and within 48 hours after the intervention to determine the effect of the intervention. The evaluation of functional fitness levels was conducted using the Senior Functional Test (Rikli and Jones 2012). The Senior Functional Test was found to be an effective tool when testing functional 


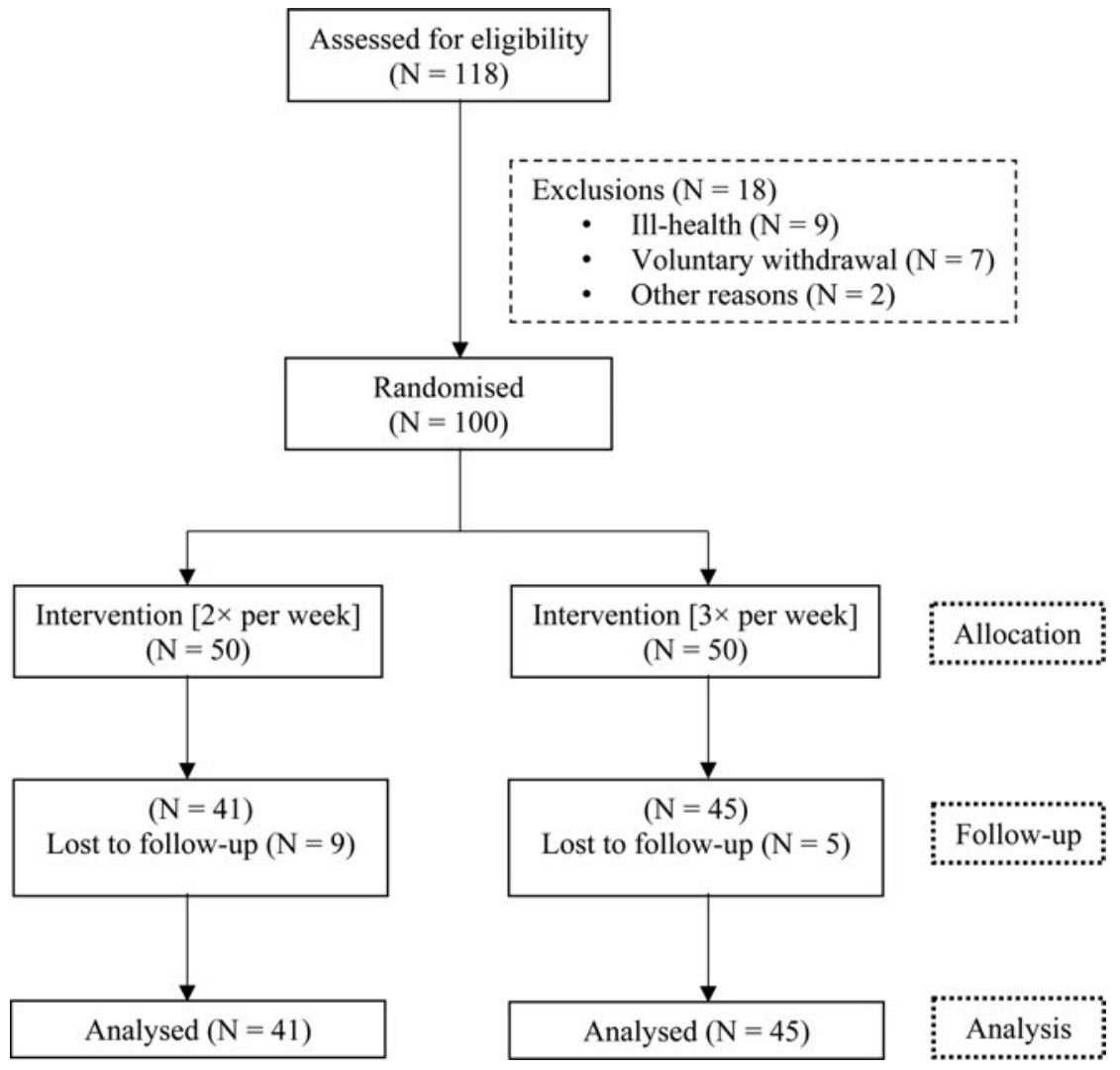

Figure 1. Participant selection and testing process.

fitness levels in this population. Its uniqueness is that it is comprehensive, i.e. it includes all physiological parameters needed to perform common everyday activities, it provides continuous-scale measures and is suitable enough to be used in a community setting. The battery included the following test components; arm curl, chair stand, back scratch, chair sit and reach, sixminute walk and eight foot up and go test, which evaluated upper and lower body strength and flexibility, aerobic endurance, agility and dynamic balance, respectively. Group 1 received the exercise intervention programme three times a week for 12 weeks, while group 2 received the same intervention but only twice a week (Table 1). Participants completed each exercise session as a group at the same time, under the guidance of an instructor. The exercise intervention was implemented and follow-up assessments were conducted immediately after the 12-week programme had ended, at each of the five facilities. Exercises began at a low intensity and increased in intensity, volume and duration. Participants were further 
TA B LE 1. Exercise intervention programme

\begin{tabular}{|c|c|c|c|}
\hline Activity & Intensity (RPE) & Duration & Resistance \\
\hline \multicolumn{4}{|l|}{ Phase 1: weeks 1-4: } \\
\hline $\begin{array}{l}\text { Warm-up: forward walk and turn, semi-tandem walk, tandem walk, circle } \\
\text { walking, sit to stand, double side arm raise (seated), neck flexion } \\
\text { (seated), neck rotation (seated), ankle - four-way (seated) }\end{array}$ & 2 (easy) & $10 \mathrm{~min}$ & \\
\hline $\begin{array}{l}\text { Endurance: weaving (station 1), step up and over (station } 2 \text { ), shuttle walk } \\
\text { (station } 3 \text { ), high knees/butt kicks (station } 4 \text { ) }\end{array}$ & 3 (moderate) & $\begin{array}{r}2.5 \min \times 4 \\
(10 \min )\end{array}$ & \\
\hline $\begin{array}{l}\text { Resistance: ball squat, wall push up, hip extension, seated bicep curl, calf } \\
\text { raises, seated triceps extension, seated lateral shoulder raises, seated } \\
\text { arm/leg march, seated rowing, seated abdominal crunches }\end{array}$ & 3 (moderate) & $\begin{array}{l}10 \text { stations } \\
(\times 10 ; 1 \text { set })\end{array}$ & $\begin{array}{l}\text { (1) Body weight; (2) dumbbells } \\
(1-2 \mathrm{~kg}) ;(3) \text { exercise band } \\
\text { (red) }\end{array}$ \\
\hline $\begin{array}{l}\text { Cool-down: forward walk/march, neck/shoulder/chest stretch, seated } \\
\text { rhomboid stretch, seated tricep stretch, lats/oblique stretch, hamstring } \\
\text { stretch, gastrocnemius stretch }\end{array}$ & 2 (easy) & $5 \min$ & \\
\hline \multicolumn{4}{|l|}{ Phase 2: weeks $5^{-8}$} \\
\hline $\begin{array}{l}\text { Warm-up: forward walk and turn, semi-tandem walk, tandem walk, circle } \\
\text { walking, sit to stand, double side arm raise (seated), neck flexion } \\
\text { (seated), neck rotation (seated), ankle - four-way (seated) }\end{array}$ & 2 (easy) & $10 \mathrm{~min}$ & \\
\hline $\begin{array}{l}\text { Endurance exercise: weaving (station 1), step up and over (station } 2 \text { ), } \\
\text { shuttle walk (station } 3 \text { ), high knees/butt kicks (station } 4 \text { ) }\end{array}$ & 4 (sort of hard) & $\begin{array}{r}3 \cdot 5 \min \times 4 \\
(14 \min )\end{array}$ & \\
\hline $\begin{array}{l}\text { Resistance exercise: ball squat, wall push up, hip extension, seated bicep } \\
\text { curl, calf raises, seated triceps extension, seated lateral shoulder raises, } \\
\text { seated arm/leg march, seated rowing, seated abdominal crunches }\end{array}$ & 4 (sort of hard) & $\begin{array}{l}10 \text { stations } \\
(\times 10 ; 2 \text { sets })\end{array}$ & $\begin{array}{l}\text { (1) Body weight; (2) dumbbells } \\
(3-4 \mathrm{~kg}) ;(3) \text { exercise band } \\
\text { (blue) }\end{array}$ \\
\hline
\end{tabular}


TABLE 1 . ( Cont.)

\begin{tabular}{|c|c|c|c|}
\hline Activity & Intensity (RPE) & Duration & Resistance \\
\hline $\begin{array}{l}\text { Cool-down: forward walk/march, neck/shoulder/chest stretch, seated } \\
\text { rhomboid stretch, seated tricep stretch, lats/oblique stretch, hamstring } \\
\text { stretch, gastrocnemius stretch }\end{array}$ & 2 (easy) & $5 \min$ & \\
\hline \multicolumn{4}{|l|}{ Phase 3 : weeks 9-12: } \\
\hline $\begin{array}{l}\text { Warm-up: forward walk and turn, semi-tandem walk, tandem walk, circle } \\
\text { walking, sit to stand, double side arm raise (seated), neck flexion } \\
\text { (seated), neck rotation (seated), ankle - four-way (seated) }\end{array}$ & 2 (easy) & $10 \mathrm{~min}$ & \\
\hline $\begin{array}{l}\text { Endurance exercise: weaving (station 1), step up and over (station } 2 \text { ), } \\
\text { shuttle walk (station } 3 \text { ), high knees/butt kicks (station } 4 \text { ) }\end{array}$ & $\begin{array}{l}4 / 5 \text { (sort of } \\
\text { hard/hard })\end{array}$ & $\begin{array}{l}5 \min \times 4(20 \\
\min )\end{array}$ & \\
\hline $\begin{array}{l}\text { Resistance exercise: ball squat, wall push up, hip extension, seated bicep } \\
\text { curl, calf raises, seated triceps extension, seated lateral shoulder raises, } \\
\text { seated arm/leg march, seated rowing, seated abdominal crunches }\end{array}$ & $\begin{array}{c}4 / 5 \text { (sort of } \\
\text { hard/hard })\end{array}$ & $\begin{array}{l}10 \text { stations } \\
\quad(\times 10 ; 2 \text { sets })\end{array}$ & $\begin{array}{l}\text { (1) Body weight; (2) dumbbells } \\
(3-4 \mathrm{~kg}) ;(3) \text { exercise band } \\
\text { (blue/green) }\end{array}$ \\
\hline $\begin{array}{l}\text { Cool-down: forward walk/march, neck/shoulder/chest stretch, seated } \\
\text { rhomboid stretch, seated tricep stretch, lats/oblique stretch, hamstring } \\
\text { stretch, gastrocnemius stretch }\end{array}$ & 2 (easy) & $5 \min$ & \\
\hline
\end{tabular}

Notes: RPE: rating of perceived exertion. min: minute. kg: kilogram. 
encouraged to discontinue exercise and seek medical intervention should they experience major warning signs/symptoms such as chest pain, palpitations or light-headedness. The desired intensity of exercise was determined using the Borg Category-Ratio-10 (CR-10) scale (Eston 2012). An explanation of this rating scale was provided to participants prior to the intervention to ensure proper understanding and maintenance of exercise intensity. Table 1 reflects the intervention programme as well as the progression of exercises. A combined programme of strength, endurance and balance activities was used, while intensity and volume progressed every four weeks. Each exercise session began with a warm-up and concluded with a cool-down. The warm-up was dynamic in nature and included both joint mobility and balance exercises. The cool-down included slow rhythmic movements and static stretches of the major muscle groups of the body. Endurance training included drills that stressed the cardiovascular system, such as weaving between cones, stepping up and over an aerobic step, shuttle walks, high knees and butt kicks. Intensity was progressed by increasing the step height and time of endurance activity. Resistance training involved movement of the upper and lower extremity large muscle groups using body weight, dumbbells and resistive exercise training bands. Increments in weight began from the lightest and increased progressively according to tolerance levels of participants over each phase.

\section{Statistical analysis}

Data were analysed using the Statistical Package for Social Science version 20.1. A value of $p<0.05$ was considered to be statistically important. The Kolmogorov-Smirnov test was used to test for normality of baseline and follow-up data. A paired $t$-test and Wilcoxon matched-pair signed rank test were used to analyse normally distributed and non-parametric data, respectively. Chi-square tests were used to analyse nominal and order (categorical) data. Analysis of covariance (ANCOVA) was performed to detect differences in baseline measures between groups. To emphasise clinical significance Cohen's $d$ effect sizes (ES) were also calculated, with the magnitude of the standardised effects interpreted using thresholds of o.o-0.2 (trivial), 0.2-0.6 (small), o.61.2 (moderate) and >1.2 (large), respectively (Hopkins et al. 2009).

\section{Results}

Demographic profile

A total of 118 participants were tested as a baseline but this number was reduced to 86 patients with valid results for the follow-up. The main 
reason for the decrease in number was due to ill-health through various stages of the intervention, with ailments ranging from common influenza to both acute and chronic respiratory conditions, which prevented some participants from sustaining exercise over the 12-week period. Other factors included the withdrawal of participants at various stages throughout the duration of the study. The mean age and standard deviation of the group was $72.87 \pm 7.54$ years, respectively. Of the 86 participants tested, 79.9 per cent were female while 22.1 per cent were male, representing a greater ratio of females to males (4:1). The South African National Consensus of 2011 reiterates this disparity by reporting a 5.02 per cent difference in ratio, in favour of females versus males in this population.

The racial composition of the sample indicates that nearly three-quarters of the patients were of South African Indian origin $(74 \%)$. Whites and Coloureds $^{1}$ represented 14 and 11 per cent, respectively, while Blacks accounted for the smallest grouping in the sample at 1 per cent. While this composition may not be reflective of the current demographic trends in the province of KwaZulu-Natal or South Africa, all five old-age homes used in the study were located in predominately Indian areas within the KwaZulu-Natal municipality.

\section{Training frequency}

The effect of frequency of exercise (between both groups of participants) on each variable was tested using multivariate analysis (Table 2). The magnitude of the standardised effect showed very little significant difference between both groups for most variables. The arm curl (right and left), as well as the chair sit and reach tests were the only variables demonstrating a moderate to large effect, with the other variables demonstrating small and trivial effects. ANCOVA was also performed to detect any differences at baseline that could account for the differences in the response to training frequency between both groups (Table 3). No statistical significance was noted. This suggests that training three times a week may have no added benefit for improving functional fitness levels compared with training twice a week in this population.

\section{Functional fitness measures}

All the variables satisfied the condition for normality except the chair sit and reach, and the eight-foot up and go tests, respectively.

There were significant improvements over time for five of the six pairings (Table 2). These were the chair stand, arm curls (for both right and left arms), chair sit and reach, back scratch and six-minute walk tests, 
T А В LE 2. Multivariate analysis and effect sizes of both study groups before and after intervention

\begin{tabular}{|c|c|c|c|c|c|}
\hline & \multirow{2}{*}{$\begin{array}{l}\text { Group 1: exercise } \\
\text { three times a week }\end{array}$} & \multirow{2}{*}{$\begin{array}{l}\text { Group 2: exercise } \\
\text { twice a week }\end{array}$} & \multirow[b]{2}{*}{$p$} & \multicolumn{2}{|c|}{ Cohen's $d$ effect sizes (95\% CI) } \\
\hline & & & & Group 1 & Group 2 \\
\hline $\mathrm{N}$ & \multicolumn{2}{|c|}{ Mean values $(S D)^{41}$} & & & \\
\hline \multicolumn{6}{|l|}{ Chair stand: } \\
\hline Baseline & $13.6(4.6)$ & $12.1(3.8)$ & 0.123 & \multirow[t]{2}{*}{ Small, $0.43(0.02,0.85)$} & \multirow[t]{2}{*}{ Moderate, $0.74(0.29,1.18)$} \\
\hline 12 Weeks & $15.6(4.8)$ & $14.9(4 \cdot 3)$ & 0.362 & & \\
\hline \multicolumn{6}{|c|}{ Arm curl - right: } \\
\hline Baseline & $13.6(4.5)$ & $13.0(4 \cdot 3)$ & 0.828 & \multirow[t]{2}{*}{ Large, $1.25(0.80,1.70)$} & \multirow[t]{2}{*}{ Large, $1.20(0.73,1.67)$} \\
\hline 12 Weeks & $19.6(5.1)$ & $18.9(5 \cdot 5)$ & 0.499 & & \\
\hline \multicolumn{6}{|c|}{ Arm curl - left: } \\
\hline Baseline & $14.2(4.7)$ & $13.9(4.2)$ & 0.917 & \multirow[t]{2}{*}{ Large, $1.20(0.75,1.65)$} & \multirow[t]{2}{*}{ Large, $1.27(0.79,1.74)$} \\
\hline 12 Weeks & $20.1(5.1)$ & $19 \cdot 9(5 \cdot 2)$ & 0.893 & & \\
\hline \multicolumn{6}{|c|}{ Chair sit and reach: } \\
\hline Baseline & $-10.2(12.4)$ & $-15.0\left(\begin{array}{lll}1 & 1.1\end{array}\right)$ & 0.049 & \multirow[t]{2}{*}{ Moderate, $0.67(0.24,1.10)$} & \multirow[t]{2}{*}{ Large, $1.93\left(1.4^{1}, 2.4^{6}\right)$} \\
\hline 12 Weeks & $-2.6(10.2)$ & $-4.9(9.4)$ & 0.145 & & \\
\hline \multicolumn{6}{|l|}{ Back scratch: } \\
\hline Baseline & $-8.6(13.5)$ & $-15.2(8.4)$ & 0.008 & \multirow[t]{2}{*}{ Trivial, $0.02(-0.44,0.39)$} & \multirow[t]{2}{*}{ Small, $0.49(0.05,0.92)$} \\
\hline 12 Weeks & $-8.9\left(\begin{array}{lll}1 & 1 & .3\end{array}\right)$ & $-11.1(8.5)$ & 0.297 & & \\
\hline \multicolumn{6}{|c|}{ Eight-foot up and go: } \\
\hline Baseline & $8.2(3.1)$ & $8.8(3.3)$ & 0.369 & \multirow[t]{2}{*}{ Small, $0.42(-0.84,-0.01)$} & \multirow[t]{2}{*}{ Trivial, $0.17(-0.60,0.27)$} \\
\hline 12 Weeks & $6.9(3.0)$ & $8.1(5.0)$ & 0.087 & & \\
\hline \multicolumn{6}{|c|}{ Six-minute walk: } \\
\hline Baseline & $374.39(136.9)$ & $3^{18.7}(121.8)$ & 0.078 & \multirow[t]{2}{*}{ Small, $0.43\left(0.01,0.8_{5}\right)$} & \multirow[t]{2}{*}{ Small, 0.49 (0.05, 0.93) } \\
\hline 12 Weeks & $427.2(106.7)$ & $375.6(108.6)$ & 0.053 & & \\
\hline
\end{tabular}

Notes: CI: confidence level. SD: standard deviation. 
TABLE 3. Differences at baseline in response to training frequency (ANCOVA)

\begin{tabular}{lcrc}
\hline & df & \multicolumn{1}{c}{ Mean } & \multicolumn{1}{c}{$p$} \\
\hline Chair stand & 1 & $2.35^{1}$ & 0.667 \\
Arm curl - right & 1 & 6.183 & 0.619 \\
Arm curl - left & 1 & 0.005 & 0.988 \\
Chair sit and reach & 1 & 11.765 & 0.710 \\
Back scratch & 1 & 0.047 & 0.982 \\
Eight-foot up and go & 1 & $7.35^{2}$ & 0.367 \\
Six-minute walk & 1 & $7,74^{1.142}$ & 0.269 \\
\hline
\end{tabular}

Notes: ANCOVA: analysis of covariance. df: degrees of freedom.

respectively $(p<0.05)$. Further inspection of the mean and standard deviation values indicated increases in all but one of the functional fitness measures post-intervention, i.e. the eight-foot up and go test. Increases in chair stand, arm curls, chair sit and reach, back scratch and six-minute walk measures demonstrated improvements in upper and lower body strength, upper and lower body flexibility, and aerobic endurance in this population following the intervention of 12 weeks of group exercise. However, no increase in the eight-foot up and go scores were noted, which suggested no improvement in participant's agility and dynamic balance following the intervention.

\section{Discussion}

The primary finding of the study was that there was no significant difference in functional fitness training two times versus three times a week. Both training frequencies resulted in increases in functional fitness levels.

Upper and lower body strength was evaluated using the arm curl (for both left and right hand) and 3o-second chair stand tests, respectively. This study found that both upper and lower body strength had improved following the 12-week intervention programme. Sustaining optimal strength levels, both in upper and lower body, is imperative, especially in older adults, for preserving physical function, preventing chronic diseases and performing activities of daily living. Many common tasks such as hand gripping, lifting and transferring rely heavily on upper body strength (Forrest, Zmuda and Cauley 20o6). The evaluation and maintenance of upper and lower body strength is critical in preventing and delaying the onset of disability, frailty and dependency during the ageing process. Studies have clearly indicated that improvements in upper and lower body strength are 
an essential factor in maintaining functional ability in later years (Garatachea et al. 2009; Paterson and Warburton 2010). This study showed similar improvements to DiBrezzo et al. (2005) who reported an increase in upper and lower body strength following a ten-week exercise programme, with strengthening exercises on every alternate day, suggesting that strengthening of both anterior and posterior muscles of the lower extremity may improve dynamic balance and agility (DiBrezzo et al. 2005).

Measures of upper and lower body flexibility were evaluated using the back scratch, and chair sit and reach tests, respectively. The results indicate that there was a significant improvement in flexibility post-intervention. Flexibility is a fundamental capacity within the ageing process (Gremeaux et al. 2012). The development of musculoskeletal impairments together with the progression of disabilities in the older adult is associated with decreases in flexibility (Holland et al. 2002). Fatouros et al. (2002) explained that declines in flexibility are related to the deterioration of functional ability and health status, which in turn leads to dysfunction and the inability to perform everyday activities such as getting up from a chair or bed, walking and climbing stairs (Fatouros et al. 2002). Wilkin and Haddock (2011) further suggested that individuals who maintain higher levels of muscular strength and flexibility seldom participate in long-term health-care programmes (Wilkin and Haddock 2011). Additional studies further reported an association between decreases in flexibility and the frequency of falls in this population (Barker et al. 2015; Karlsson et al. 2013; Milanović et al. 2013).

Agility and dynamic balance was assessed using the eight-foot up and go test. The results indicate that there was no improvement in agility and dynamic balance following the intervention programme, which is in contrast to other reviewed studies of this nature (Brito et al. 2014). Agility and balance are critical in performing a vast array of common mobility tasks. These include walking, climbing stairs and effecting quick movements to avoid hazardous obstacles, going to the bathroom, to get on and off private and public transport vehicles, to cross the street, or to answer the telephone or the door. Though there are few studies related to the parameters of agility and dynamic balance related to age, the results of some have shown that this component decreases with increasing age (Toraman, Erman and Agyar 2004). Findings suggest agility and dynamic balance is best improved and the risk of falling reduced if specific balance and coordination activities are included in exercise programmes, together with strength, flexibility and aerobic activities (Correa Bautista et al. 2011). Evidence indicates that performances in the eight-foot up and go test can discriminate among various functional categories in this population, and is reactive to changes that can result from increased levels of physical activity 
(Alexander et al. 2001). In this regard, Miotto et al. (1999) found that physically active individuals who are 6o years and older performed faster (4.9 seconds) than their sedentary counterparts $(5.7$ seconds) in the eight-foot up and go scores (Miotto et al. 1999). Other studies similarly reported the average eight-foot up and go scores to be considerably faster in a highly active group than those of a low active group (Rikli and Jones 1999). In a study conducted by Liu-Ambrose et al. (2004), resistance training and agility training significantly reduced fall risk scores by 57 and 48 per cent, respectively, following a 25 -week intervention programme (Liu-Ambrose et al. 2004). These findings could suggest three different explanations why there were no improvements in agility and dynamic balance in the present study. Firstly, the 12 -week intervention programme may not be sufficient to provide improvements in balance and agility levels; secondly, the sample population used in this study may not have been at an adequately high enough physical activity level; and thirdly, the proprioceptive activities used in the intervention may not have been of a sufficient level needed to improve balance and agility measures satisfactorily in those 60 years and older.

Aerobic capacity was evaluated using the six-minute walk test. The results indicate a significant improvement in aerobic capacity following the intervention protocol. The average distance covered in six minutes increased from 348.40 metres prior to the intervention to 402.38 metres post-intervention. Declines in aerobic capacity occur throughout the lifespan, accelerating much faster in later years. The rate of decline in aerobic capacity appears to decline by a rate of $5^{-15}$ per cent per decade (Hollenberg et al. 2006; Weiss et al. 2006). This age-related decline in aerobic capacity has the potential to predispose individuals who are 6o years and older to common comorbidities such as pulmonary, cardiac and peripheral arterial diseases, while aerobic-type activities have been shown to exert beneficial effects on blood pressure, lipids, glucose tolerance, bone density, depression and quality of life (Fleg 2012; Maguire and Slater 2013). Reference equations and tables are often used to predict the six-minute walk test distance in healthy subjects over the age of 6o years, with the gender, age, weight and height of participants often explaining the large proportion of variability in the distances covered (Hulens et al. 2003). However, progressing age is supplemented by an increase in pathologies and 'apparently healthy' older citizens can present a larger diversity when it comes to health status. This infers that exercise capacity and the risk for complications during exercise may not necessarily be the same for each person, especially those who consider themselves capable of performing physical activity (Izaks and Westendorp 2003). Ideally, the exercise programme should be tailor-made for each individual, taking into account all facets of the 
individual's health condition. However, the influence of health status to the variability of distance covered in the six-minute walk test has yet to be meticulously and extensively described (Bautmans, Lambert and Mets 2004).

When comparing both groups of participants, the results indicate no significant difference in functional fitness levels between group 1 (exercise undertaken three times a week) and group 2 (exercise undertaken twice a week). Although a statistically significant difference was observed in the back scratch test $(p<0.05)$, the findings reveal only a trivial to small magnitude of effect. Stiggelbout et al. (2004) suggested that although group exercise was well suited to this population, participation only twice a week without additional regular physical exercise did not provide the stimulus needed to bring about improvements in functional fitness levels (Stiggelbout et al. 2004). Similar findings reported that participation in exercise programmes twice a week was insufficient for this population, while others suggested that older women who participated in an exercise programme three times a week gained greater functional fitness benefits than those who exercised less frequently (Nakamura et al. 2007; Puggaard 2003). In contrast, the present study has shown that improvements in functional fitness levels may not necessarily be achieved with a greater frequency of participation in group exercise programmes. The results indicate that participation just twice a week can provide the required dosage deemed necessary to elicit improvements in functional fitness levels in persons who are 60 years and older.

\section{Conclusion}

The results demonstrated that 12 weeks of progressive, multifaceted group exercise increased strength, flexibility and aerobic endurance levels in individuals who are 60 years of age and older. This study concurs with similar research studies demonstrating the importance of physical activity in improving functional fitness levels in the elderly, and thus their overall health. The intervention programme is a viable option that can be easily implemented in any facility that provides care for the older adult. It has a low operational cost, easy applicability and can be performed by many individuals across different fitness levels at the same time. Finally, the study demonstrated that participation in a group exercise programme twice a week was an adequate dose to improve overall functional fitness levels in this population, with an extra session a week adding no further improvement. 
1870 Levin Chetty et al.

\section{Acknowledgement}

The University of KwaZulu-Natal, College of Health Sciences supported the study.

\section{NOTE}

1 Coloured is the South African race label given to people of mixed race.

\section{References}

Alexander, N. B., Gross, M. M., Medell, J. L. and Hofmeyer, M. R. 2001. Effects of functional ability and training on chair-rise biomechanics in older adults. Journals of Gerontology: Biological Sciences and Medical Sciences, 56A, 9, M538-47.

Armitage-Johnson, S. 1994. Safety tips: providing a safe training environment, Part II. Strength and Conditioning Journal, 16, 2, 34 .

Barker, A. L., Talevski, J., Bohensky, M.A., Brand, C.A., Cameron, P.A. and Morello, R. T. 2015 . Feasibility of Pilates exercise to decrease falls risk: a pilot randomized controlled trial in community-dwelling older people. Clinical Rehabilitation, 3o, 10, 1-13.

Bautmans, I., Lambert, M. and Mets, T. 2004. The six-minute walk test in community dwelling elderly: influence of health status. BMC Geriatrics, 4, 1, 6.

Brink, H., Van der Walt, C. and Van Rensburg, G. H. 201 2. Fundamentals of Research Methodology for Health Care Professionals. Juta, Cape Town.

Brito, L. V. de O., Neto, G. A. M., Helena, M. and Deslandes, A. C. 2014. Relationship between level of independence in activities of daily living and estimated cardiovascular capacity in elderly women. Archives of Gerontology and Geriatrics, 59, 2, 367-71.

Brown, M. and Holloszy, J. O. 1993. Effects of walking, jogging and cycling on strength, flexibility, speed and balance in 6o- to 72 -year olds. Aging (Milan), 5, $6,427-34$.

Chin, A., Paw M., van Poppel, M., Twisk, J. and van Mechelen, W. 2004. Effects of resistance and all-round, functional training on quality of life, vitality and depression of older adults living in long-term care facilities: a 'randomized' controlled trial. BMC Geriatrics, 4, 1, 5.

Correa Bautista, J. E., Gámez Martínez, E. R., Ibáñez Pinilla, M. and Rodríguez Daza, K. D. 2011. Physical fitness in older woman related to an active aging program. Revista de La Universidad Industrial de Santander, Salud, 43, 3, 263-9.

Daley, M. J. and Spinks, W. L. 2000. Exercise, mobility and aging. Sports Medicine, 29, $1,1-12$.

DiBrezzo, R., Shadden, B. B., Raybon, B. H. and Powers, M. 2005. Exercise intervention designed to improve strength and dynamic balance among community-dwelling older adults. Journal of Aging and Physical Activity, 13, 2, 198-209.

Duthie, P. R. and Malone, M. L. 2007. Practice of Geriatrics. Fourth edition, Saunders Elsevier, Philadelphia.

Eston, R. 201 2. Use of ratings of perceived exertion in sports. International Journal of Sports Physiology and Performance, 7, 2, 175-82.

Fatouros, I. G., Taxildaris, K., Tokmakidis, S. P., Kalapotharakos, V., Aggelousis, N., Athanasopoulos, S. and Katrabasas, I. 2002. The effects of strength training, cardiovascular training and their combination on flexibility of inactive older adults. International Journal of Sports Medicine, 23, 2, 11 2-9. 
Fleg, J. L. 2012. Aerobic exercise in the elderly: a key to successful aging. Discovery Medicine, 13, 70, 223-8.

Forrest, K. Y.Z., Zmuda, J. M. and Cauley, J. A. 2006. Patterns and correlates of muscle strength loss in older women. Gerontology, 53, 3, 140-7.

Garatachea, N., Molinero, O., Martínez-García, R., Jiménez-Jiménez, R., GonzálezGallego, J. and Márquez, S. 20og. Feelings of well being in elderly people: relationship to physical activity and physical function. Archives of Gerontology and Geriatrics, 48, 3, 306-12.

Gremeaux, V., Gayda, M., Lepers, R., Sosner, P., Juneau, M. and Nigam, A. 2012. Exercise and longevity. Maturitas, 73, 4, 312-7.

Holland, G. J., Tanaka, K., Shigematsu, R. and Nakagaichi, M. 2002. Flexibility and physical functions of older adults: a review. Journal of Aging and Physical Activity, 1o, 2, $169-206$.

Hollenberg, M., Yang, J., Haight, T. J. and Tager, I. B. 20o6. Longitudinal changes in aerobic capacity: implications for concepts of aging. Journals of Gerontology: Biological Sciences and Medical Sciences, 61A, 8, 851-8.

Hopkins, W., Marshall, S., Batterham, A. and Hanin, J. 2009. Progressive statistics for studies in sports medicine and exercise science. Medicine and Science in Sports and Exercise, 41, 1, 3-12.

Hulens, M., Vansant, G., Claessens, A. L., Lysens, R. and Muls, E. 2003. Predictors of 6-minute walk test results in lean, obese and morbidly obese women. Scandinavian Journal of Medicine and Science in Sports, 13, 2, 98-105.

Izaks, G.J. and Westendorp, R. G.J. 2003. Ill or just old? Towards a conceptual framework of the relation between ageing and disease. BMC Geriatrics, 3, 1, 7 .

Joubert, J., Norman, R., Lambert, E. V., Groenewald, P., Schneider, M., Bull, F. and Bradshaw, D. 2007. Estimating the burden of disease attributable to physical inactivity in South Africa in 2000. South African Medical Journal, 97, 8, 725-31.

Karlsson, M. K., Magnusson, H., Von Schewelov, T. and Rosengren, B. E. 2013. Prevention of falls in the elderly - a review. Osteoporosis International, 24, 3, 747-62.

Liu-Ambrose, T., Khan, K. M., Eng, J.J., Janssen, P. A., Lord, S. R. and Mckay, H. A. 2004. Resistance and agility training reduce fall risk in women aged 75 to 85 with low bone mass: a 6-month randomized controlled trial. Journal of the American Geriatrics Society, $\mathbf{5}^{2}, 5,657-65$.

Lopez, A. D., Mathers, C. D., Ezzati, M., Jamison, D. T. and Murray, C. J. L. 2006. Global and regional burden of disease and risk factors, 2001: systematic analysis of population health data. The Lancet, $\mathbf{3 6}_{7}, 95^{24}, 1747-57$.

Lunenfeld, B. 2008. An aging world-demographics and challenges. Gynecological Endocrinology, 24, 1, 1-3.

Maguire, S. L. and Slater, B. M. J. 2013. Physiology of ageing. Anaesthesia and Intensive Care Medicine, 14, 7, 310-2.

Marques, A., Rosa, M., Soares, P., Santos, R., Mota, J. and Carvalho, J. 2011. Evaluation of physical activity programmes for elderly people $-\mathrm{a}$ descriptive study using the EFQM' criteria. BMC Public Health, 11, 1, 123.

Milanović, Z., Pantelić, S., Trajković, N., Sporiš, G., Kostić, R. and James, N. 2013. Age-related decrease in physical activity and functional fitness among elderly men and women. Clinical Interventions in Aging, 8, 549-56.

Miotto, J. M., Chodzko-Zajko, W.J., Reich, J. L. and Supler, M. M. 1999. Reliability and validity of the Fullerton Functional Fitness Test: an independent replication study. Journal of Aging and Physical Activity, 7, 4, 339-53.

Nakamura, Y., Tanaka, K., Yabushita, N., Sakai, T. and Shigematsu, R. 2007. Effects of exercise frequency on functional fitness in older adult women. Archives of Gerontology and Geriatrics, 44, 2, 163-73. 
North, B. J. and Sinclair, D. A. 201 2. The intersection between aging and cardiovascular disease. Circulation Research, 110, 8, 1097-108.

Paterson, D. H. and Warburton, D. E. R. 2010. Review: Physical activity and functional limitations in older adults: a systematic review related to Canada's Physical Activity Guidelines. International Journal of Behavioral Nutrition and Physical Activity, 7, 38, 1-22.

Paw, C. A., Marijke, J. M., van Poppel, M. N. M., Twisk, J. W. R. and van Mechelen, W. 2006. Once a week not enough, twice a week not feasible? A randomised controlled exercise trial in long-term care facilities. Patient Education and Counseling, $6_{3}, 1,205^{-14}$.

Puggaard, L. 2003. Effects of training on functional performance in $6_{5}, 75$ and 85 year-old women: experiences deriving from community based studies in Odense, Denmark. Scandinavian Journal of Medicine and Science in Sports, 13, 1, 70-6.

Rikli, R. E. 2005. Movement and mobility influence on successful aging: addressing the issue of low physical activity. Quest, 57, 1, 46-66.

Rikli, R. E. and Jones, C. J. 1999. Functional fitness normative scores for communityresiding older adults, ages 6o-94. Journal of Aging and Physical Activity, 7, 2, 162-81.

Rikli, R. E. and Jones, C.J. 2012. Senior Fitness Test Manual. Volume 1, Human Kinetics, Champaign, Illinois.

Statistics South Africa 201 2. https://statssa.gov.za/publications/Po3014/Pozo 142011. pdf

Stiggelbout, M., Popkema, D.Y., Hopman-Rock, M., De Greef, M. and Van Mechelen, W. 2004. Once a week is not enough: effects of a widely implemented group based exercise programme for older adults; a randomised controlled trial. Journal of Epidemiology and Community Health, 58, 2, 83-8.

Toraman, N. F., Erman, A. and Agyar, E. 2004. Effects of multicomponent training on functional fitness in older adults. Journal of Aging and Physical Activity, 12, 4, $53^{8-53}$.

Weiss, E. P., Spina, R. J., Holloszy, J. O. and Ehsani, A. A. 20o6. Gender differences in the decline in aerobic capacity and its physiological determinants during the later decades of life. Journal of Applied Physiology, 101, 3, 938-44.

Wilkin, L. D. and Haddock, B. L. 201 1. Functional fitness of older adults. Activities, Adaptation and Aging, 35, 3, 197-209.

Wolfson, L., Whipple, R., Derby, C., Judge, J., King, M., Amerman, P. and Smyers, D. 1996. Balance and strength training in older adults: intervention gains and Tai Chi maintenance. Journal of the American Geriatrics Society, 44, 5, 498-506.

Accepted I3 February 20I8; first published online I3 March 2018

Address for correspondence:

Levin Chetty,

Department of Physiotherapy,

University of KwaZulu-Natal,

Westville Campus, Block E1, Floor 5,

Room 22 PO Box X54001, Durban 4000, South Africa

E-mail: chettyle@ukzn.ac.za 